\title{
AVALIAÇÃO IMUNOHISTOQUÍMICA E ULTRAESTRUTURAL DE GAMETAS E EMBRIÕES CAPRINOS INFECTADOS COM O CAEV
}

\author{
A.R.F. Ricarte', A. Andrioli' ${ }^{2}$, R.R. Pinheiro ${ }^{2}$, S.N. Báo ${ }^{3}$, J.S. Silva ${ }^{3}$, S.V. Braz ${ }^{3}$, K.P.O. Name ${ }^{3}$, I.B. Lima- \\ Verde $^{4}$, I.F. Brito ${ }^{2}$, R.P. Dias ${ }^{2}$, T.D. Freitas Aguiar ${ }^{1}$, T.V.M. Dantas ${ }^{1}$, S.A.C. Araújo ${ }^{1}$, \\ D.M.L.P.Cavalcanti ${ }^{5}$, N.R.O. Paula ${ }^{1}$, M.F.S. Teixeira ${ }^{1}$
}

${ }^{1}$ Universidade Estadual do Ceará, Faculdade de Veterinária, Laboratório de Virologia, Av. Paranjana, 1700,CEP 60740-903, Fortaleza, CE, Brasil. E-mail: labovirfavetuece@yahoo.com.br

\section{RESUMO}

\begin{abstract}
O objetivo do presente estudo foi determinar a susceptibilidade dos folículos ovarianos, espermatozoides e embriões caprinos ao Vírus da Artrite Encefalite Caprina (CAEV). Para isto, foram analisados espermatozoides e folículos ovarianos pelas técnicas de imunohistoquímica e microscopia eletrônica de transmissão, antes e após protocolos de infecção in vitro com o CAEV. Foram submetidos à análise ultraestrutural, embriões caprinos produzidos in vivo, oriundos de cabras negativas e positivas para o CAEV. Nas amostras seminais, provenientes de animais tanto com infecção natural quanto dos artificialmente infectados, foi observada imunomarcação positiva dos espermatozoides, assim como alterações degenerativas na sua análise ultraestrutural. Já nas amostras de tecido ovariano, a imunomarcação foi mais discreta e identificada na região do estroma. No tocante à análise ultraestrutural, folículos e embriões se apresentaram íntegros. De acordo com esses resultados, pode-se concluir que os espermatozoides caprinos apresentaramse infectados, assinalando a susceptibilidade dessas células ao vírus, bem como a potencialidade do CAEV ser carreado ao cerne do oócito, originando embriões infectados.
\end{abstract}

PALAVRAS-CHAVE: Espermatozoides, embriões, folículos e CAEV.

\section{ABSTRACT}

IMMUNOHISTOCHEMICAL ANDULTRASTRUCTURALEVALUATIONOFGAMETESAND EMBRYOS OF GOATS INFECTED WITH CAEV. The aim of this study was to determine the susceptibility of goat ovarian follicles, spermatozoa and embryos to caprine arthritis-encephalitis virus (CAEV). Spermatozoa and ovarian follicles were analyzed, before and after in vitro infection with CAEV, through immunohistochemistry and transmission electron microscopy techniques. Goat embryos, produced in vivo from infected and non-infected goats, were submitted to ultrastructural analysis. Immunohistochemical examination of seminal samples from goats naturally and artificially infected with CAEV revealed viral antigens in spermatozoa, while the ultrastructural analysis showed degenerative changes in these cells. Ovarian tissue samples presented a more discreet immunohistochemical positive reaction situated in the stroma region. Ultrastructural analysis revealed that the embryos and ovarian follicles were intact. These results indicate that the spermatozoa were infected, confirming the susceptibility of these cells to the virus, as well as the potential of CAEV entering the oocyte, giving rise to infected embryos.

KEY WORDS: Spermatozoa, embryos, follicles and CAEV.

\section{INTRODUÇÃO}

Ovírus da artrite encefalite caprina (CAEV) provocaumaimportanteenfermidadeinfecciosa em caprinos. Este pertence ao gênero Lentivirus (CORK et al., 1974) e tem como característica preponderante causar uma enfermidadecrônica, com umlongoperíododeincubação e de difícil controle (NARAYAN, 1990), sendo as células do sistema monocítico-fagocitário o principal alvo da infecção in vivo (ZiNK et al., 1990).

\footnotetext{
${ }^{2}$ Empresa Brasileira de Pesquisa Agropecuária, Centro Nacional de Pesquisa em Caprinos, Sobral, CE, Brasil. ${ }^{3}$ Universidade de Brasília, Laboratório de Microscopia Eletrônica, Brasília, DF, Brasil.

${ }^{4}$ Universidade Estadual do Ceará, Laboratório de Manipulação de Folículos Pré-Antrais, Fortaleza, CE, Brasil. ${ }^{5}$ Universidade Federal Rural do Semiárido, Laboratório de Histologia e Embriologia, Mossoró, RN, Brasil.
} 
O DNA proviral do CAEV já foi detectado em tecidos do trato reprodutivo como útero, oviduto, ovário, glândula mamária (FIENI et al., 2002), em células do cumulus oophorus (Ali Al AhMAD et al., 2005) eem sêmen de machosinfectados (ANDRIOLIetal.,1999; Travassos et al., 1999; Ali Al AhmAd, 2008). Em estudos in vitro, este vírus demonstrou ser capaz de se replicar com eficiência em células epiteliais do oviduto (LAMARA etal., 2002) eem células da granulosa (LAMARA et al.,2001). Não tendo sido detectada ainda a presença, ou possíveis alterações provocadas por este vírus no oócito, embriões ou no interior deespermatozoides caprinos.

A principal medida de controle dessa enfermidade é o sacrifício dos animais soropositivos (RICHARD; Cullen, 1996), podendo levar, assim, a perdas de animais com alto valor genético. Na tentativa de evitar essas perdas, a biotécnica de transferência de embriões (FreITAS et al., 1999) já foi utilizada com sucesso. Neste contexto, o resgate e a utilização de material genético de animais portadores dessa enfermidade despontam como alternativas promissoras para o aproveitamento dos gametas de fêmeas e machos portadores do CAEV.

O sucesso para o aproveitamento desses gametas depende da sua qualidade e sanidade. Sendo assim, para utilização do material genético de animais soropositivos para o vírus da CAE, faz-se necessária uma avaliação da presença e dos os efeitos deste sobre a integridade dos oócitos, espermatozoides e embriões a fim de se verificar a viabilidade na utilização deste material em biotécnicas reprodutivas, uma vez queainda não foram realizadas análise ultraestrutural e imunohistoquímica de folículos ovarianos e espermatozoides caprinos submetidos à infecção natural ou in vitro pelo CAEV, como também de embriões fecundados in vivo oriundos de machos e fêmeas infectados. Desta forma, o objetivo do presente estudo foi caracterizar a ocorrência de degeneração e, ainda, a presença do vírus da artrite encefalite caprina bem como a susceptibilidade dos folículos ovarianos, espermatozoides e embriões caprinos ao mesmo.

\section{MATERIALEMÉTODOS}

\section{Delineamento experimental}

Foram analisados espermatozoides e folículos ovarianos antes e após infecção in vitro com o CAEV através das técnicas de imunohistoquímica e microscopia eletrônica de transmissão e, ainda, embriões caprinos produzidos in vivo oriundos de cabras negativas e positivas para o CAEV, os quais foram submetidos à análise ultraestrutural.

\section{Amostras de sêmen}

Foram utilizados sêmen de 10 machos caprinos, sendo4machosinfectadosnaturalmentecomoCAEV, 4 infectados experimentalmente 2 negativos, atestados pela prova de imunodifusão em gel de agarose (IDGA) e Reação em Cadeia da Polimerase (PCR). Após a coleta, cada ejaculado foi separado em antes e após o swim up.

A coleta de sêmen foi realizada através do método da vagina artificial, onde foi utilizada uma fêmea em estro para estimular o macho e, quando este efetuou o salto, o prepúcio foi desviado com a mão para o interior da vagina artificial. Em seguida, o tubo contendo o sêmen foi tampado para proteger o ejaculado da poeira, luz solar e agitação e levado para o laboratório onde foi processado. Logo após a coleta, uma alíquota $(200 \mu \mathrm{L})$ antes do swim up foi retirada e teve uma parte fixada em formol tamponado a $10 \%$ para realização da imunohistoquímica e outra parte fixada em fixador Karnovisky para realização da microscopia eletrônica de transmissão.

\section{Técnica de Swim up}

As alíquotas de cada ejaculado que foram submetidas ao swim up seguiram a metodologia descrita por GonçALVES et al. (2001), onde cerca de $200 \mu \mathrm{L}$ de cada amostra foi colocada no fundo de um tubo de centrífuga e em seguida, sobre o sêmen, o meio Gamete ${ }^{\circledR}$ (Vitrolife). Esses tubos foram colocados com inclinação para formar um ângulo de $45^{\circ}$ em estufa a $5 \%$ de $\mathrm{CO}_{2}$ e temperatura de $39^{\circ} \mathrm{C}$ por $45 \mathrm{~min}$. Em seguida, o sobrenadante rico em espermatozoides foi aspirado e transferido para outro tubo para ser centrifugado com rotação de 900 g por 10 min. Após a centrigugação, o sobrenadante foi desprezado e o pellet de espermatozoides teve uma parte destinada à imunohistoquímica e outra parte à microscopia eletrônica de transmissão.

\section{Infecção in vitro do sêmen}

Foram utilizadas para infecção in vitro apenas espermatozoides de animais negativos para o CAEV. Após a coleta seminal, foram retiradas três alíquotas de $200 \mu$ Lde sêmen puro, as quais foram colocadas em contatocomovírus $(5 \mu \mathrm{L}$ cepaCAEV-Cork-ultracentrifugado em colchão de sacarose) (ANDRIOLI-PINHEIRO, 2001). Das três alíquotas, uma ficou em contato com o CAEV por 30, outra por 60 e a última por 120 minutos. Após cada período de contato, as alíquotas foram retiradas, centrifugadas (900 g por $10 \mathrm{~min}$.), ressuspensas em PBS e, posteriormente, foi retirada uma alíquota de $100 \mu \mathrm{L}$, a qual foi fixada para microscopia eletrônica de transmissão e outra alíquota de 
mesmovolume foifixada em formol tamponadoa $10 \%$ e destinada à imunohistoquímica.

Para comprovar a capacidade infectante da cepa viral, foi realizada a infecção de células de membrana sinovial caprina nos mesmos tempos de infecção dos espermatozoides (30,60 e 120 min.). Após a infecção, as células foram mantidas em cultivo até o aparecimento de efeito citopático(ECP).

\section{Obtenção dos folículos ovarianos}

Os folículos ovarianos foram obtidos a partir de ovários provenientes de animais de abatedourolocal, sendo utilizados somente os animais que estavam comprovadamente negativos para CAEV através do teste de IDGA. A região cortical destes ovários foi então fragmentada em três partes e os fragmentos obtidos foram acondicionados em placas de 20 poços contendo Meio Essencial Mínimo (MEM - Gibco®) até o momento da infecção in vitro.

\section{Infecção in vitro dos folículos pré-antrais in situ}

Cada poço foi inoculado com a amostra padrão com do vírus (5 $\mu \mathrm{L}$ cepa CAEV-Cork - ultracentrifugado em colchão de sacarose) e ficaram em contato por 30, 60 e 120 minutos, em estufa a $5 \%$ de $\mathrm{CO}_{2}$ em temperatura de $37^{\circ} \mathrm{C}$ (CRAWFORD; AdAMS, 1981). Após este tempo, as amostras foram fixadas em formol tamponado a $10 \%$ e fixador Karowisky e destinadas à imunohistoquí-mica e microscopia eletrônica de transmissão, respectivamente.

\section{Imunohistoquímica (IHQ)}

Para a análise imunohistoquímica, onde se tentou localizar topograficamente a proteína p28 do CAEV em sêmen e ovários de caprinos, utilizou-se metodologia descrita por ARAújOet al. (2004). Foi feita a elaboração dos esfregaços das amostras seminais em lâminas histológicas, além de cortes histológicos dos ovários, com espessura de $5 \mu \mathrm{m}$ cada, sendo posteriormente realizada a recuperação de antígenos. Para isto, as lâminas foram incubadas em tampão citrato $10 \mathrm{mM}(\mathrm{pH} \mathrm{6,0)} \mathrm{com} \mathrm{o} \mathrm{auxílio} \mathrm{de} \mathrm{um} \mathrm{forno}$ micro-ondas em potência máxima (700 watts), onde as amostras foram colocadas por três vezes com três minutos de duração cada. A atividade da peroxidase endógena foi bloqueada utilizando-se 3\% de peróxido dehidrogênio $\left(\mathrm{H}_{2} \mathrm{O}_{2}\right)$ em metanol, com duas trocas de cinco minutos cada. Para bloquear as ligações inespecíficas, as amostras foram incubadas em soro canino por 20 minutos. As secções foram então tratadas com soro contendo anticorpos específicos contra o CAEV (IgG1 anti-p28), por um período de 18 horas a uma temperatura de $4^{\circ} \mathrm{C}$. Em seguida, foram lavadas em PBS e incubadas com IgG anti-caprino conjugada a peroxidase por 30 minutos a $37^{\circ} \mathrm{C}$ a uma diluição de 1:500. A reação foi revelada pela adição do diaminobenzidina tetrahidroclorídeo por 7 minutos. As lâminas foram contracoradas com hematoxilina deMayer por 1 minuto, montadas e analisadas em um microscópio óptico.

\section{Obtenção dos embriões}

Foram utilizadas 6 fêmeas caprinas da raça anglonubiana com escore corporal médio igual a 2.Destas, 4 eram positivas para o CAEV pelo teste de IDGA e 2 negativas, constituindo o grupo controle. Foi utilizado sêmen de machos negativos para inseminar as fêmeas positivas e sêmen de machos positivos para inseminar fêmeas negativas para o CAEV.

Todas as fêmeas foram submetidas ao protocolo de superovulação, onde esponjas impregnadas com medroxiprogesterona foram inseridas na vagina, sendoeste dia 0 do tratamento desuperovulação. Nodia 9 foi feita uma aplicação única de PGF $2 \alpha$ (Ciosin $®)$ e iniciou-se a aplicação de FSH (Foltropin $\AA$ ) por quatro dias consecutivos, sendo 2 aplicações diárias com intervalo de 12 horas. No dia 11 foram retiradas as esponjas, as fêmeas foram inseminadas três vezes, tendo sido realizada a primeira inseminação $24 \mathrm{~h}$ após a retirada das esponjas, quando as fêmeas apresentaram sinal de estro. Foi utilizado sêmen fresco e resfriado, tendo um tempo médio de intervalo entre as inseminações de 6 horas. Nos tempos de 72, 96 e 120 horas após as inseminações foi aplicado, por via intramuscular, Flunixin Meglumine (Banamine ${ }^{\circledR}$ ) e 84 horas após o início do estro foi aplicado LH (Lutalise®).

As coletas de embrião foram realizadas por laparotomia e lavagem dos cornos uterinos no $5^{\circ} \mathrm{e} 6^{\circ}$ dia após a última inseminação artificial, segundo metodologia descrita por ANDRIOLI-PINHEIRO (2001).

Após as coletas, as estruturas recuperadas (oócitos e embriões) foram fixadas e destinadas à análise ultraestrutural.

\section{Microscopia Eletrônica de Transmissão}

Para análise ultraestrutural dos espermatozoides, foi retirada uma alíquota de $100 \mu \mathrm{L}$ do ejaculado, a qual foi lavada três vezes em PBS. As amostras de tecido ovariano com tamanho de $1 \mathrm{~mm}^{3}$, os embriões e oócitos recuperados foram acondicionadas separadamente em tubos eppendorf. Posteriormente, todas as amostras foram fixadas por 12 horas a $4^{\circ} \mathrm{C}$ em fixador Karnovisky (2\% de paraformaldeídoe 2,5\% de glutaraldeído em tampão cacodilato de sódio 0,1 M com pH 7,2). Após esta fixação, as amostras foram lavadas com solução tampão 0,1 M de Cacodilato de Sódio e pós-fixadas em tetróxido de ósmio 1\% e 0,8\% 
de ferricianeto de potássio. Em seguida, foram desidratadas com acetona eimpregnadas em resina epóxi Sppur. Antes da confecção dos cortes ultrafinos, foram preparadas secções semifinas $(3 \mu \mathrm{m})$ as quais foram coradas com azul de toluidina. Posteriormente, foram confeccionados os cortes ultrafinos ( $90 \mathrm{~nm}$ ), os quais foram contrastados com acetato de uranila e citrato de chumbo, para que então pudessem ser examinados no microscópio eletrônico de transmissão (Jeol). As amostras foram então analisadas quanto à presença do CAEV, bem como a presença de alterações degenerativas.

\section{RESULTADOS}

\section{Imunohistoquímica}

$\mathrm{Na}$ imunohistoquímica, as amostras seminais oriundas de animais infectados naturalmente apresentaram imunomarcação positiva em 2 amostras antes do swim up. Nas amostras pertencentes a animais infectados experimentalmente, observou-se imunomarcação em uma amostra antes e em outra depois do swim up (Fig. 1). Nas duas amostras infectadas in vitro também foi observada imunomarcação positiva (Fig. 2), indicando a presença da proteína p28 do CAEV. Vale ressaltar que este achado ainda não havia sido descrito na literatura para este tipo celular.

Nas amostras ovarianas, observou-se marcação positiva em apenas uma amostra na região doestroma
(Fig. 3), não tendo sido apresentada nenhuma marcação nas células da granulosa ou no oócito.

\section{Microscopia eletrônica de transmissão}

$\mathrm{Na}$ avaliação ultraestrutural foram observados espermatozoides normais eíntegros, tendo sido verificadonogrupo dos animaisinfectados naturalmente apenas sinais de degeneração tais como a presença de vesículas na região da peça intermediária.

Os folículos de cabras infectadas encontrados na microscopia eletrônica de transmissão estavam normais, sem sinais de alteração, com um núcleo oocitário íntegro, localizado no centro do oócito e organelas distribuídas uniformemente no citoplasma. As mitocôndrias apresentaram membrana mitocondrial contínua e crista periférica. Também foi observada a presença de retículo endoplasmático liso e as células da granulosa apresentavam-se normais.

$\mathrm{Na}$ análise ultraestrutural dos embriões foram observadas zona pelúcida intacta, espaço perivitelínico e massa celular interna constituída por células de aspecto irregular, com núcleo oval localizado centralmente. No citoplasma foi observada a presença de retículo endoplasmático rugoso, polirribossomos e mitocôndrias. Observou-se também oócitos não fertilizados, que apresentaram zona pelúcida íntegra e células internas degeneradas, porém, em ambas estruturas recuperadas (embriões e oócitos), não foi verificada a presença de qualquer partícula viral no seu interior ou aderido a porção externa da zona pelúcida.

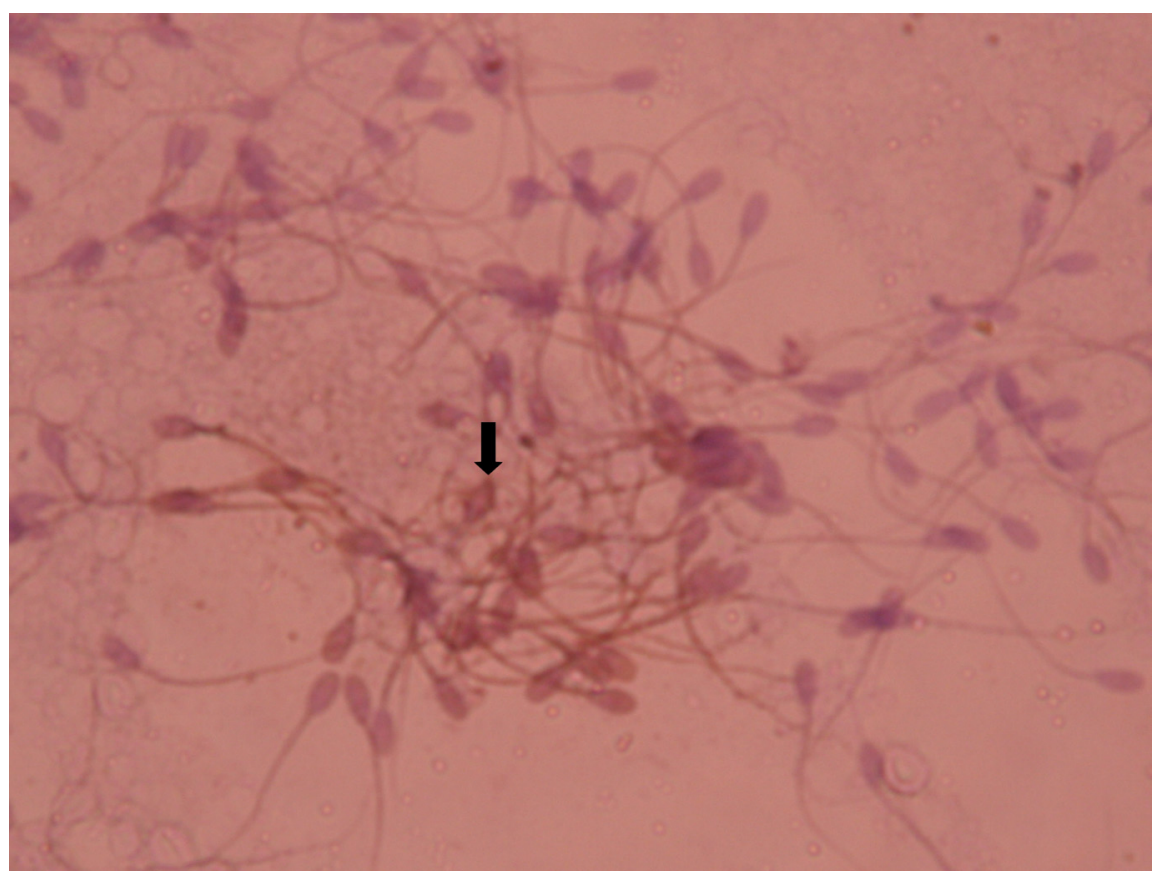

Fig. 1 - Espermatozoides caprinos submetidos à imunohistoquímica demonstrando marcação positiva (seta). (Aumento 400X). 


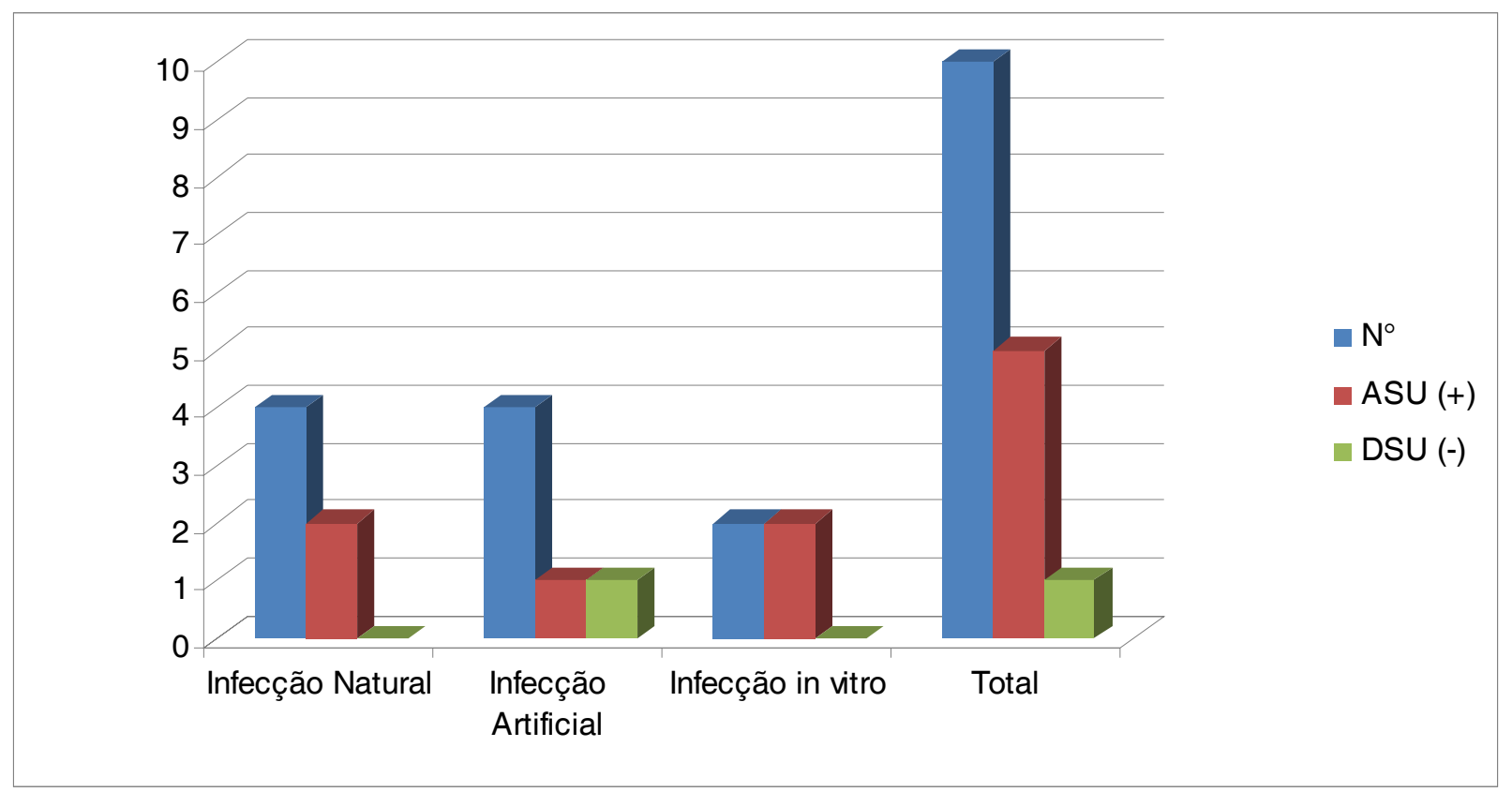

Fig. 2 - Amostras seminais testadas pela imunohistoquímica antes do swim up (ASU) e depois (DSU) nos diferentes grupos.

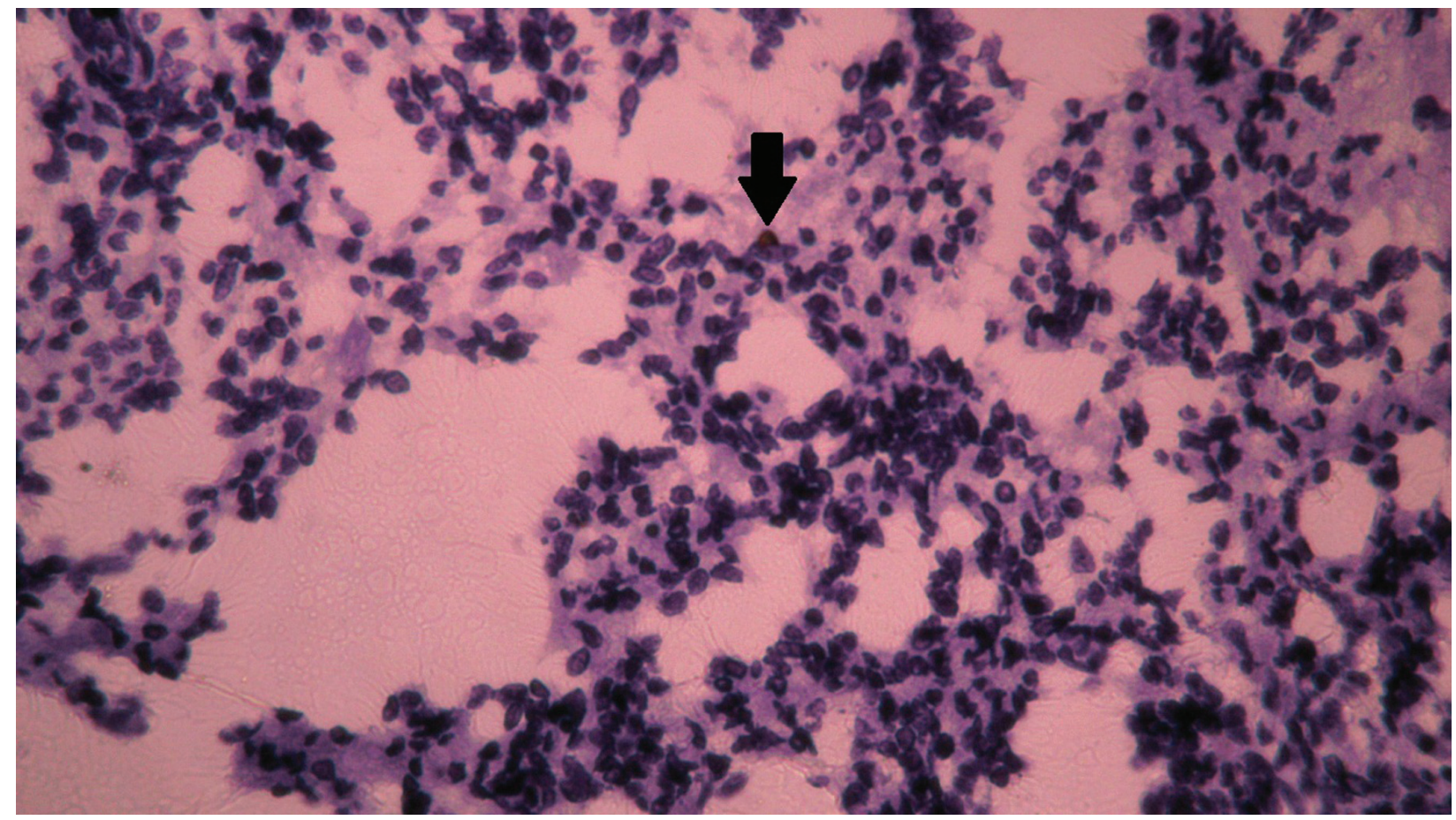

Fig. 3 - Tecido ovariano submetido à imunohistoquímica demonstrando marcação positiva em fibroblasto do estroma (seta). (Aumento 100X).

\section{DISCUSSÃO}

Como foi demonstrado neste trabalho, na imunohistoquímica observou-se a presença da proteína p28 do CAEV nos espermatozoides. Os achados anteriores se baseavam na detecção do CAEV em pulmão de caprinos (PEREIRA, 1995; SERAKIDEs et al., 1996; StORSET et al. 1997, GuEDes et al., 2001) e de outro Lentivirus, o Maedi Visna Vírus (MVV), o qual já foi detectado por imunomarcação em pulmão (ARAújoet al., 2004), em hepatócitos e em células cardíacas (BRELLOU et al., 2007). 
Com esta demonstração da susceptibilidade de espermatozoides ao CAEV, presume-se que estes possam ser veiculadores do CAEV para o embrião, apesar de se ter a comprovação de quea zona pelúcida funciona como uma barreira efetiva contra e entrada de patógenos (Ali Al AHMAD et al., 2005), desde que estes não sejam carreados pelo espermatozoide no momento da fecundação, fenômeno esse que já foi comprovado em embriões humanos fertilizados com espermatozoides de homens infectados com o HIV (BACCETI et al., 1998). Vale ressaltar que o HIV é um vírus pertencente ao gênero Lentivirus, o mesmo do CAEV (CORK et al., 1974).

Com relação a ausência de marcação positiva nos folículos na imunohistoquímica dos ovários, os achados contradizem as colocações de LAMARA et al. (2001) e Ali Al AHMAD et al. (2005), os quais observaram que as células da granulosa e do cumulus são susceptíveis ao CAEV. Porém, corroboram as afirmações de ZinK et al. (1990) que confirmam ser as células de predileção da infecção do CAEV as células do sistema monocítico fagocitário e fibroblastos, principais componentes da membrana sinovial caprina e córtex ovariano.

Na análise ultraestrutural dos folículos ovarianos das cabras infectadas foi observado folículos normais com as mesmas características de folículos de cabras sadias como observados por Lucci et al. (2001), Silva et al. (2002) e Ricarte (2005).

A avaliação ultraestrutural dos embriões caprinos oriundos de fêmeas infectadas comoCAEV foi realizada pela primeira vez nesta espécie.Os achados não revelaram a presença de partícula viral no interior deles, bem como demonstraram características ultraestruturais semelhantes as de embriões equinos, conforme descrito por Pereset al. (2007).

Apesardeterverificadoqueos espermatozoides caprinos são susceptíveis ao $\mathrm{CAEV}$, não se observou a presença de partículas virais no interior de embriões. Isto pode ser explicado pelo fato da presença do CAEV no sêmen ser intermitente(ANDRIOLIetal.,2003), ou seja, pode estar associado a possibilidade de nem todos espermatozoides apresentarem receptores para este vírus. Sendo assim, pode ter ocorrido que os espermatozoides utilizados na inseminação dos animais poderiam nãoestar infectados, ou simplesmente porqueo vírus apresentava-senoestágio deDNA próviral, impossibilitando a visualização da partícula viral pela microscopia eletrônica de transmissão.

\section{CONCLUSÃO}

Com esses resultados pode-se concluir que os folículos ovarianos apresentaram discreta imuno- marcação na região do estroma, enquanto os espermatozoides caprinos mostraram-se infectados, assinalando a susceptibilidade dessas células ao vírus, bem como a potencialidade doCAEV ser carreado ao cerne do oócito, originando embriões infectados.

\section{AGRADECIMENTOS}

Os autores agradecem à EMBRAPA-CNPC, pelo apoio financeiro, técnico e científico para realização deste experimento. À Coordenação de Aperfeiçoamento de Pessoal de Ensino Superior (CAPES), pelo apoio financeiro, em forma de bolsa cedida à doutoranda Aracely R. F. Ricarte durante oexperimento. Ao Laboratório de Microscopia Eletrônica da Universidade de Brasília e ao Laboratório de Virologia da Universidade Estadual do Ceará, pelo apoio técnicocientífico.

\section{REFERÊNCIAS}

ALI AL AHMAD, M.Z.; FIENI, F.; MARTIGNAT, L. Proviral DNA of caprine arthritis encephalitis virus (CAEV) is detected in cumulus oophorus cells but not in oocytes from naturally infected goats. Theriogenology, v.41, p.41-67, 2005.

ALI AL AHMAD, M.Z.; FIENI, F.; PELLERIN, J.L.; GUIGUEN, F.; CHEREL, Y.; CHATAGNON, G.; BOUZAR, A.B.; CHEBLOUNE, Y. Detection of viral genomes of caprine arthritis-encephalitis virus (CAEV) in semen and in genital tract tissues of male goat. Theriogenology, v.69, n.4, p.473-480, 2008.

ANDRIOLI, A.; GOUVEIA, A.M.G.; PINHEIRO, R.R. Deteç̧ão do DNA pró-viral do lentivírus caprino em sêmen de bodes naturalmente infectados. Revista Brasileira de Reprodução Animal, v.23, n.3, p.420-420, 1999.

ANDRIOLI-PINHEIRO, A. Virus da Artrite Encefalite Caprina: PCR e isolamento viral em amostras de sêmen, fluido uterino e embriões. 2001. 68p. Tese (Doutorado) Universidade Federal de Minas Gerais, Belo Horizonte, 2001.

ANDRIOLI, A.; GOUVEIA, A.M.G.; PINHEIRO, R.R. Seleção de sêmen de reprodutores portadores do vírus da artrite encefalite caprina através da técnica de reação em cadeia da polimerase. Sobral: EMBRAPA-CNPC, 2003. 23p. (Comunicado técnico, n.50).

ARAÚJO, S.A.C; DANTAS, T.V.M.; SILVA, J.B.A.; RIBEIRO, A.L.; RICARTE, A.R.F.; TEIXEIRA, M.F.S. Identificação do Maedi-Visna Vírus em Pulmão de Ovinos Infectados Naturalmente. Arquivos do Instituto Biológico, São Paulo, v.71, n.4, p.431-436, 2004. 
BACCETTI, B.; BENEDETTO, A.; COLLODEL, G.; CARO, A.; GARBUGLIA, A.R.; PIOMBONI, P. The debate on the presence of HIV-1 in human gametes. Journal of Reproductive Immunology, v.41, p.41-67, 1998.

BRELLOU, G.D.; ANGELOPOULOU,K.;POUTAHIDIS, T.; VLEMMAS, I. Detection of Maedi-Visna Virus in the liver and heart of naturally infected sheep. Journal of Comparative Pathology, v. 136, p. 27-35, 2007.

CORK, L.C.; HADLON, W.J.; CRAWFORD, T.B. Infectious leucoencephalomyelitis of young goats. Journal of Infectious Diseases, v.129, n.2, p.134-141, 1974.

CRAWFORD, T.B.; ADAMS, D.S. Caprine arthritisencephalitis: clinical features and presence of antibody in selected populations. Journal of the American Veterinary Medical Association, v.178, p.713-719, 1981.

FIENI, F.; ROWE, J.; VAN HOOSEAR, K.; BURUCOA, C.; OPPENHEIM, S.; ANDERSON, G.; MURRAY, J.; BONDURANT, R. Presence of caprine arthritisencephalitis virus (CAEV) infected cells en flushing media following oviductal-stage embryo collection. Theriogenology, v.57, p.931-940, 2002.

FREITAS, V.J.F.; CAVALCANTE, T.V.; SALLES, H.O.; TEIXEIRA, M.F.S. Embryo transfer from seropositive goats for caprine arthritis-encephalitis virus (CAEV) with birth of seronegative kid. Ciência Animal, v.9, n.1, p.5-9, 1999.

GONÇALVES, P.B.D.; VISITIN, J.A.; OLIVEIRA, M.A.L.; MONTAGNER, M.M.; COSTA, L.F.S. Produção in vitro de embriões. In: Biotécnicas aplicadas a reprodução animal. GONÇALVES, P.B.D.; FIGUEIREDO, J.R.; FREITAS, V.J.F. (Ed.). São Paulo: Livraria Varela, 2001. p. 195-226.

GUEDES, M.I.M.C.; SOUZA, J.C.A.; GOUVEIA, A.M.G. Infecção experimental em cabritos pelo vírus da artrite encefalite. Arquivo Brasileiro de Medicina Veterinária e Zootecnia, v.53, 2001.

LAMARA, A.; FIENI, F.; MSELLI-LAKHAL, L.; TAINTURIER, D.; CHEBLOUNE, Y. Eficient replication of caprine arthritis encephalitis vírus in goat granulose cell. Virus Research, p.79, p.165-172, 2001.

LAMARA, A.; FIENI, F.; MSELLI-LAKHAL, L.; CHATAGNON, G.; BRUYAS, J.F.; TAINTURIER, D.; BATTUT, I.; FORNAZERO, C.; CHEBLOUNE, Y. Early embryonic cells from in vivo-produced goat embryos transmit the caprine arthritis-encephalitis virus (CAEV). Theriogenology, v.58, n.6, p.1153-1163, 2002.

LUCCI, C.M.; SILVA, J.R.V.; CARVALHO, F.C.A.; BÁO, S.N. Light microscopical and characterization of goat preantral follicles. Small Ruminant Research, v.41, p.6169, 2001.
NARAYAN, O. Immunopathology of lentiviral infections in ungulate animals. Current Opinion in Immunology, v.2, n.3, p.399-402, 1990.

PEREIRA, M.F. Artrite-encefalite caprina a virus (CAE): Estudo anatomopatológico e imuno-histoquímico em cabras naturalmente infectadas. 1995. 57p. Dissertação (Mestrado) - Universidade Federal de Minas Gerais, Escola de Veterinária, Belo Horizonte, 1995.

PERES, K.R.; FERNANDES, C.B.; ALVARENGA, M.A.; LANDIM-ALVARENGA, F.C. Análise da viabilidade e da ultra-estrutura de embriões obtidos de éguas superovuladas. Veterinaria e Zootecnia, v.14, n.1, p.52-61, 2007.

RICHARD, R.E.; CULLEN, G.A. (Ed.). Manual of standard for diagnostic tests and vaccines. 3.ed. Paris: OIE, 1996. p.369-373.

RICARTE, A.R.F. Caracterização morfológica e ultraestrutural de folículos pré-antrais de cabras naturalmente infectadas com vírus da artrite encefalite caprina. 2005. $60 \mathrm{f}$. Dissertação (Mestrado em Ciências Veterinárias) Faculdade de Veterinária, Universidade Estadual do Ceará, Fortaleza, 2005.

SERAKIDES, R.; NUNES, V.A.; PEREIRA, M.F. Estudo clínico, anatomopatológico e imuno-histoquímico de pulmões de cabras naturalmente infectadas pelo vírus da artrite encefalite caprina (CAE). Arquivo Brasileiro de Medicina Veterinária e Zootecnia, v.48, p.415-424, 1996.

SILVA, J.R.V.; FERREIRA, M.A.L.; COSTA, S.H.F.; SANTOS, R.R.; CARVALHO, F.C.A.; LUCCI, S.M.; BÁO, S.N.; FIGUEIREDO, J.R. Degeneration rate of preantral follicles in the ovaries of goats. Small Ruminant Research, v.43, p.203-209, 2002.

STORSET, A.K., EVENSEN, O., RIMSTAD, E. Immunohistochemical identification of caprine arthritis-encephalitis virus in paraffin-embedded specimens from naturally infected goats. Veterinary Pathological, v.34, p.180-188, 1997.

TRAVASSOS, C.; BENÔIT, C.; VALAS, S. Caprine arthritis-encephalitis virus in semen of naturally infected bucks. Small Ruminantt Research, v.32, p.101106, 1999.

ZINK, M.C.; YAGER, J.A.; MYERS, J.D. Pathogenesis of caprine arthritis-encephalitis virus cellular localization of viral transcripts in tissues of infected goats. American Journal of Pathology, v.136, p.843-854, 1990.

Recebido em 10/12/08

Aceito em 2/6/10 